\title{
Estratégias de gerenciamento na Atenção Primária à Saúde em territórios de vulnerabilidade social expostos à violência*
}

\author{
Primary Healthcare management strategies in socially vulnerable territories exposed to violence \\ Estrategias de gestión en Atención Primaria de Salud en territorios de vulnerabilidad social \\ expuestos a la violencia
}

Como citar este artigo:

Nonato LOF, Peres AM, Khalaf DK, Souza MAR, Figueiredo KC, Lapierre J. Primary Healthcare management strategies in socially vulnerable territories exposed to violence. Rev Esc Enferm USP. 2020;54:e03608. doi: https://doi.org/10.1590/S1980-220X2018054903608

\author{
Lívia Oliveira Fernandes Nonato ${ }^{1}$ \\ Aida Maris Peres ${ }^{1}$ \\ Daiana Kloh Khalaf ${ }^{1}$ \\ Marli Aparecida Rocha de Souza ${ }^{1}$ \\ Karla Crozeta Figueiredo ${ }^{1}$ \\ Judith Lapierre ${ }^{2}$ \\ * Extraído da dissertação: "Gerenciamento \\ de serviços de atenção primária à saúde \\ em territórios expostos a violência urbana”, \\ Programa de Pós-Graduação em Enfermagem, \\ Universidade Federal do Paraná, 2018. \\ ${ }^{1}$ Universidade Federal do Paraná, \\ Programa de Pós-Graduação em \\ Enfermagem, Curitiba, PR, Brasil \\ ${ }^{2}$ Université Laval, Faculte des Sciences \\ infirmieres, Quebec, QC, Canadá.
}

\begin{abstract}
Objective: To identify management strategies used by the Family Health Strategy teams of a Basic Health Unit in organizing work in socially vulnerable territories exposed to violence. Method: A single case study with a qualitative approach in a family health unit located in the southern region of Brazil. Data collection was conducted through individual interviews with 27 health professionals from August to September 2017 and a focus group with 18 participants in April 2018. Data organization and processing was performed with the support of the IRAMUTEQ software program and subsequently the content analysis technique. Results: The five classes characterized strategies used by professionals to provide care to the population considering their experience in facing violent situations. A guideline was developed and validated in the focus group to guide the management and organization of work in these services. Conclusion: It was evidenced that professionals develop strategies which include strengthening the team as a form of collective protection, welcoming focused on comprehensive care and bonding, even without the support of specific public policies for these situations. The population is allied to facilitate access to care for vulnerable people and alerts professionals to critical situations in the territory.
\end{abstract}

\section{DESCRIPTORS}

Violence; Social Vulnerability; Health Personnel; Primary Care Nursing; Family Health. 


\section{INTRODUÇÃO}

A Atenção Primária à Saúde (APS) constitui o primeiro ponto de atenção e a principal porta de entrada da Rede de Atenção à Saúde (RAS) do Sistema Único de Saúde (SUS), sendo responsável por ordenar o cuidado, os fluxos e os contrafluxos das pessoas na RAS. No Brasil, a APS pode contar ainda com a Estratégia de Saúde da Família (ESF) como estratégia de expansão e consolidação no território nacional ${ }^{(1)}$.

A ESF possui como princípios norteadores para a sua prática: o cuidado centrado na pessoa e na família, o vínculo com o usuário e a população, a integralidade, a coordenação do cuidado, a articulação à rede assistencial, a participação social e a atuação intersetorial. Essas potencialidades buscam respostas à maioria das necessidades de saúde da população que atende, oferecendo ações de promoção, prevenção, recuperação da saúde, reabilitação de doenças e vigilância de agravos mais frequentes. Ações estas que podem ser minimizadas quando inseridas em territórios complexos e diversificados ${ }^{(2)}$.

A organização do trabalho das equipes da ESF está baseada em uma APS territorializada a partir de uma população adscrita, em um local geograficamente delimitado. $\mathrm{O}$ território, compreendido como um espaço dinâmico e em constante mudança, está sujeito à variabilidade de riscos e vulnerabilidades sociais. Para as equipes de ESF, este espaço, ao ser considerado vivo e dinâmico, é capaz de produzir e reproduzir o processo saúde-doença, que analisado sob a ótica epidemiológica, permite identificar fatores e condições relacionadas aos processos de determinação social ${ }^{(3)}$. Nesta lógica, território é fruto do processo histórico, político e social que influencia o modo como as pessoas vivem e, no tocante à organização do trabalho das equipes de ESF, desde o reconhecimento das necessidades de saúde até o planejamento das ações a serem desenvolvidas.

O enfrentamento da violência pelos profissionais e gerentes de serviços de saúde é evento recente que causa tensão e medo. Ao se depararem com um fenômeno social complexo que exige uma abordagem ampla, integral e multidisciplinar, possivelmente por uma formação pautada no modelo biomédico e intervencionista, eles ainda não sabem ao certo como agir ${ }^{(4)}$. $\mathrm{O}$ fenômeno atinge em média um a cada dois profissionais em todo mundo, além disso, $25 \%$ dos atos violentos no trabalho acontecem no setor de saúde ${ }^{(5)}$. Todavia, a violência não causa impacto somente aos profissionais, mas diretamente na qualidade dos serviços ofertados à população, seja no acesso desta aos serviços ou na prática dos profissionais de saúde ${ }^{(5-6)}$.

Frente ao contexto exposto, esta pesquisa objetivou identificar as estratégias de gerenciamento utilizadas pelas equipes de ESF de uma Unidade Básica de Saúde na organização do trabalho em um território de vulnerabilidade social exposto à violência.

\section{MÉTODO}

\section{TIPO DO ESTUDO}

Estudo de caso único com abordagem qualitativa. $\mathrm{O}$ estudo de caso é utilizado em muitas situações e contribui para o conhecimento de fenômenos grupais e organizacionais ${ }^{(7)}$.

\section{CenÁrio}

Unidade Básica de Saúde (UBS) com três equipes de ESF de uma cidade da região sul do Brasil, localizada em uma área de alta vulnerabilidade social. Cerca de 97\% de sua população utiliza os serviços oferecidos pela unidade de forma exclusiva e seu território encontra-se em quarto lugar dentre os maiores índices de vulnerabilidade social da cidade, índice calculado pelo IVAB - Índice de Vulnerabilidade das Áreas de Abrangência das Unidades Municipais de Saúde e que define a distribuição equitativa dos recursos do município. E que foi estabelecido a partir do Índice de Vulnerabilidade das Famílias do Paraná -IVF-PR e da população do censo do IBGE 2010 por área de abrangência. Para o cálculo do IVAB, foi utilizado como critério, uma lista com famílias residentes no município, com IVF-PR final superior a 0,2798, o que denota alta vulnerabilidade e no qual a região da pesquisa foi classificada como $0,256^{(8)}$.

Este território, por sua posição geográfica com saídas rápidas do local e da cidade, facilitou o surgimento da venda e tráfico de drogas. Com esse cenário, ao longo de sua história, surgiram conflitos pela obtenção do poderio da venda de drogas. Uma via de muita movimentação que corta o território ao meio e dividiu o bairro com a denominação de "gangue de cima", localizada acima da via, e "gangue de baixo", situada abaixo da via. Por esse e outros motivos, o cenário desta pesquisa enfrenta diversas situações de violência.

Durante reunião de equipe, todos os profissionais efetivos e terceirizados da UBS que atuam no cenário da pesquisa foram convidados por uma das pesquisadoras a participar e esse foi o critério de inclusão para ambas as etapas. Porém, somente na primeira etapa utilizou-se como critério de exclusão: residentes, estagiários e profissionais afastados. Já na segunda etapa, o critério de exclusão foi somente profissionais afastados.

\section{Coleta de Dados}

Ocorreu em duas etapas, a primeira entre agosto e setembro de 2017, com entrevistas semiestruturadas com profissionais das três equipes da UBS, no total de 38. Nesta etapa, 27 participaram da pesquisa e que estiveram presentes durante a coleta, os demais estavam em afastamentos lícitos e/ou alocados em outros postos, ressaltando-se que não houve recusa de nenhum participante. Foram utilizadas perguntas que estiveram ligadas a: (1) se haviam presenciado e/ou sofrido violência e se havia intenção em transferir-se da unidade; (2) e se utilizavam alguma estratégia na prevenção da violência em seu local de trabalho. Cada entrevista durou em média oito minutos, foram gravadas e realizadas em uma sala separada, no próprio serviço.

A segunda etapa ocorreu em abril de 2018, quando se compôs um grupo focal com 18 profissionais que estavam presentes na reunião de equipes na UBS, sendo esta já agendada como programação específica da unidade de pesquisa. Entre estes participantes, estavam os que já haviam participado da primeira etapa. Todos os presentes na reunião de equipes aceitaram participar da segunda etapa e os motivos das ausências 
dos outros profissionais, estiveram ligadas às mesmas justificativas, acima referenciadas. $\mathrm{O}$ grupo focal durou uma hora e meia e foi gravado com a presença de duas observadoras que fizeram anotações, entre elas uma das autoras.

\section{ANÁLISE E TRATAMENTO DOS DADOS}

Para o processamento dos dados da primeira etapa, após transcrição das entrevistas gravadas e confecção do corpus, foi utilizado o software IRAMUTEQ - Interface de $R$ pour les Analyses Multidimensionneles de Textes et de Questionnaires. O corpus é um texto descrito de forma direta, em um único arquivo do tipo texto.txt do software OpenOffice.org, separados por linhas de comando, de acordo com as variáveis da pesquisa. Esta fase permitiu a identificação rápida de todo o segmento de texto utilizado na escrita qualitativa com rigor científico, sendo a análise de total responsabilidade do pesquisador ${ }^{(9)}$. Esse software é gratuito ancorado no ambiente estatístico do software $\mathrm{R}$, que viabiliza várias análises de dados textuais.

Esta pesquisa utilizou a classificação Hierárquica Descendente (CHD), que divide inicialmente o corpus em segmentos de texto (ST) em função de seus vocábulos e de acordo com a frequência das formas reduzidas obtendo-se, assim, as classes de unidades de contexto elementares (UCE). Ocorre então a criação do dicionário de palavras com a utilização do teste qui-quadrado $\left(\chi^{2}\right)$, que revela a associação de força entre elas, analisada quando o teste for maior que 3,84 , o que representa $\mathrm{p}<0,0001$, e o aproveitamento dos ST deve ser maior que $75 \%$. O IRAMUTEQ então organiza os dados de forma ilustrativa em um dendrograma, que demonstra as relações e os vocábulos das classes ${ }^{(10)}$. A partir desta organização dos dados, as pesquisadoras iniciaram sua análise.

$\mathrm{Na}$ segunda etapa, de grupo focal, após a transcrição da gravação, realizou-se a técnica de análise de conteúdo de Bardin, na modalidade análise temática, na qual é possível aprofundar-se na leitura, esclarecendo uma parcela de significados que poderiam induzir uma descrição que antes não se havia compreensão ${ }^{(11)}$. As transcrições da gravação das entrevistas, bem como do grupo focal, não foram devolvidas para os participantes para comentário e/ou correções.

Os resultados levaram à confecção de um quadro categorial, que privilegiou a repetição dos temas durante a reunião em um processo de decifração estrutural centrado nas falas, de forma não sistemática, e com flexibilidade por conta do próprio material verbal. Análise que consistiu na transversalidade temática, separando as falas por temas representados por letras em ordem alfabética ${ }^{(11)}$.

\section{Aspectos éticos}

Esta pesquisa foi realizada com os preceitos da Resolução no 466/2012, do Conselho Nacional de Saúde e submetida a dois Comitês de Ética em Pesquisa, da Universidade Federal do Paraná, aprovado sob o Parecer no 2.159.123/17 e da Secretaria de Municipal da Saúde de Curitiba, sob o Parecer no 2.234.609/17. Os profissionais que aceitaram participar da pesquisa assinaram o Termo de Consentimento Livre e Esclarecido (TCLE), com a garantia do sigilo, através da utilização de código de identificação na primeira etapa (P) e a na segunda (PGS), ambos acrescidos de sequência numérica.

\section{RESULTADOS}

O processamento dos dados pelo software IRAMUTEQ durou 16 segundos e foram obtidos 265 ST, com aproveitamento de 207 ST, o que equivale a 78,11\%. Como parâmetro de análise foi utilizado um qui-quadrado maior que 9 na relação entre as UCEs, sendo que algumas palavras mesmo quando destacadas pelo sistema não foram analisadas devido à forma de expressão utilizada pelos participantes, gerando o dendrograma (Figura1).
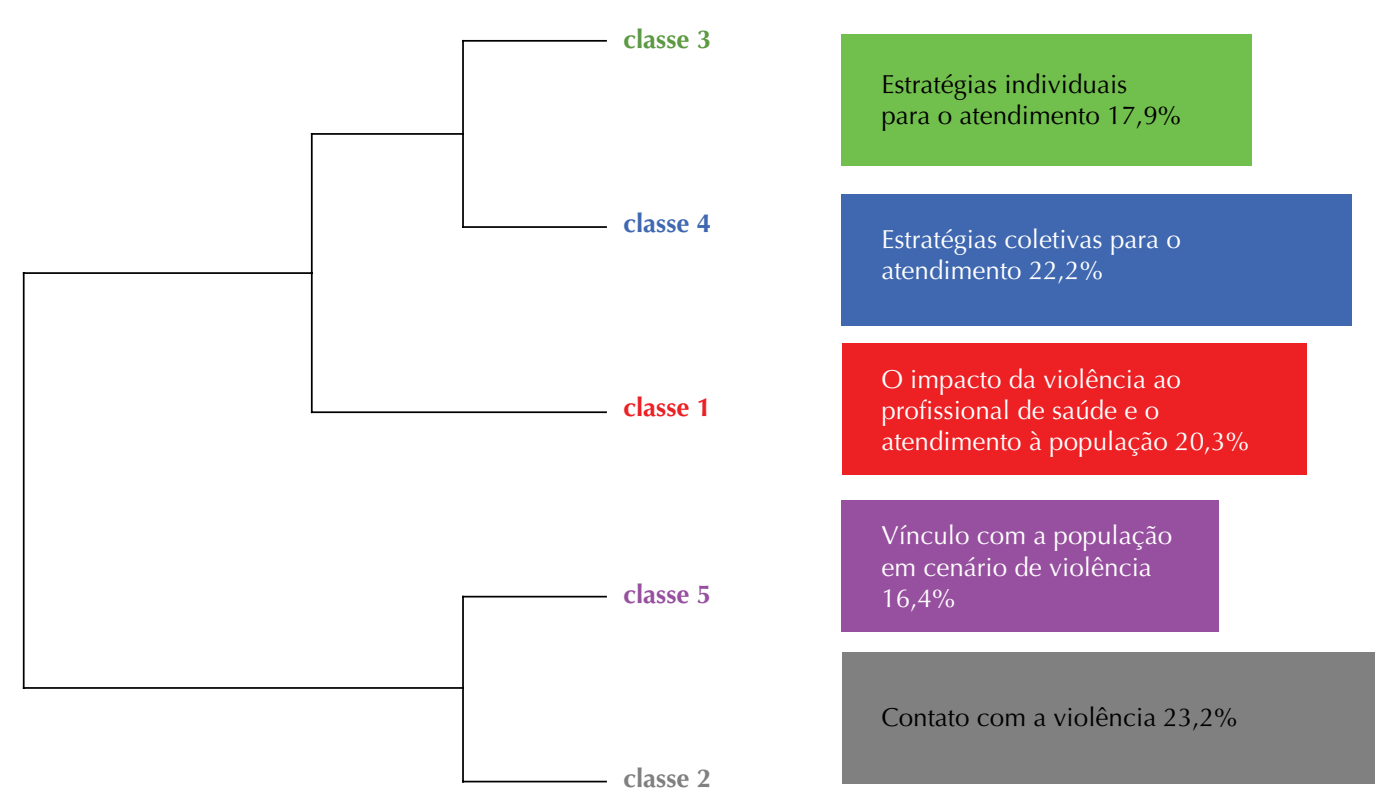

Figura 1 - Dendrograma das classes fornecidos pelo Software IRAMUTEQ. 
A leitura para relacionar as classes do dendrograma deve ser realizada da esquerda para a direita, de baixo para cima. $\mathrm{Na}$ Figura 1 pode-se observar que o corpus foi dividido em duas partes: de um lado dois sub-corpus, a classe 2 com 48 UCEs $(23,2 \%)$ e a classe 5 com 34 UCEs $(16,4 \%)$ e do outro, a classe 1 com 42 UCEs (20,3\%). A classe 1 teve nova divisão e gerou a classe 3 com 37 UCEs (17,9\%) e classe 4 com 46 UCEs $(22,2 \%)$ totalizando 207 UCEs (100\%), o que promoveu a estagnação da CHD pela estabilização dos ST nos vocábulos semelhantes. A percentagem referente ao conteúdo está relacionada à quantidade de vezes em que as palavras inseridas nos ST se repetem em relação ao total do corpus $^{(10)}$. As palavras então foram analisadas no contexto das falas e as classes intituladas pela pesquisadora, conforme demonstra a Figura 1. A seguir são descritas as classes após a análise da primeira etapa.

Classe 1, referenciada como: o impacto da violência ao profissional de saúde e o atendimento à população. Ressaltam-se as palavras: medicação, visita domiciliar, ficar e guerra. Os profissionais relataram sua atuação diária e a relação desse contexto com o impacto pessoal acerca da violência, com destaque às seguintes considerações:

Você vê o resultado daquilo [da violência] e realmente acaba machucando a gente (...), eu tive [atendi] uma criança com ferimento por arma de fogo na face e é uma coisa muito traumatizante, a gente acaba sendo atingido (P01).

Nesta classe surgiram ainda situações nas quais o medo e o temor são explicitados e a violência ocorre dentro da unidade de saúde.

(...) desarmaram um rapaz aqui dentro [da unidade de saúde] e ficaram com a arma de fogo dele e depois eles vieram resgatar a arma e ai (...) quando eu vi um monte de rapazes querendo pular e invadir o posto, fiquei bastante preocupada, medo de morrer mesmo (P03).

Em outra perspectiva, com relação ao impacto da violência ao atendimento à população, um dos participantes apontou o seguinte:

Quando teve aquela situação de violência na área, a guerra das gangues, a gente ficava alguns dias sem fazer visita domiciliar e isso afetava os pacientes por causa da falta de visitas (P17).

Classe 2, referenciada como: contato com a violência. As palavras que obtiveram maior destaque de associação foram: trabalhar, pensar, sair, gosto, população e movimento. Esta classe evidenciou o contato direto com a violência e como se organizam para se protegerem.

Um rapaz levou um tiro, tentou entrar na unidade e não conseguiu e morreu ali na frente e a esposa estava grávida e ficou ali segurando uma sombrinha para não ir [bater] sol no corpo dele até chegar o SLATE. Isso me marcou bastante (P18).

Falas com abordagem sobre a forma como conseguem avisar uns aos outros, nas situações de perigo no território, com destaque aos Agentes Comunitários de Saúde (ACS) e a comunidade nesses momentos:

A gente procura através das ACS e da comunidade, e eles acabam nos falando oh, hoje tá muito tenso, tomem cuidado (P01).
As ACS sempre avisam a gente, (...) qualquer coisa que esteja acontecendo diferente na Vila, então a gente tenta se comunicar - quanto antes pelo Whatsapp ${ }^{\circledR}$ para se proteger e se resguardar (P03).

Classe 3, referenciada como: estratégias individuais para $o$ atendimento. As palavras que se destacaram foram: conversar, procurar, falar, tentar, certo, evitar, dizer, jeito, contato e alterar. Relataram-se estratégias utilizadas individualmente, ligadas à comunicação, para evitar ou minimizar conflitos dentro da UBS, com ênfase à forma de abordagem aos usuários.

Tomar cuidado para suavizar o máximo [a resposta] não. Porque às vezes, um não que a gente fala, eles interpretam como uma coisa pessoal e ai pode gerar consequências ( $\mathrm{P} 03)$.

A importância de se manter uma relação amistosa e leve entre os pares dentro da UBS foi alegada no intuito de manter um ambiente de trabalho calmo e tranquilo:

Sempre digo para mantermos um ambiente de trabalho tranquilo porque já basta a violência lá fora, a gente tenta pelo menos não deixar que isso afete tanto (...) (P18).

Classe 4, referenciada como: estratégias coletivas para o atendimento. Os destaques foram: atendimento, resolver, problema, momento, atender, usuário, unidade de saúde e complicado. Os participantes descreveram estratégias coletivas que se somam às individuais pelo envolvimento da equipe em atendimento no território com esse cenário. Sobressaem-se seus sentimentos de proteção ao colega, a tranquilidade e a assertividade na comunicação com o usuário a fim de evitar conflitos, assim como a utilização de meio de comunicação disponível e rápido como o Whatsapp $^{\circledR}$ para avisar sobre possibilidades de riscos no território. Salienta-se ainda nesta classe o uso do jaleco como forma de identificação do profissional de saúde.

Olha, a gente é bem companheiro um do outro, se a gente vê que um colega teve uma situação de apuro, se um colega está passando uma situação difícil, eu tento entrar e amenizar a situação ali e resolver. Assim que a gente age aqui (P08).

O que nos protege são os jalecos brancos (P19).

Classe 5, referenciada como: vínculo com a população em cenário de violência com destaque para: violência, maior, considerar, agressão, profissional, família e vivenciar. Os profissionais descreveram que, apesar do impacto da violência, possuem vínculo com a população e se sentem úteis. Distingue-se nessa classe o sentimento de não querer sair da UBS.

Não tenho esse sentimento [de sair do serviço por conta da violência] eu acho que a gente é muito útil aqui, principalmente na saúde da familia, a gente tem um envolvimento maior, você tem um vinculo (P19).

Nunca! [sair da unidade por conta da violência]. É um dos melhores locais onde já trabalhei. (...) Das comunidades que trabalhei, eu considero que [essa] é a que mais necessita do meu trabalho profissional, onde eu vejo realmente um resultado imediato de muitas das minhas intervençôes. E eu considero de fácil acesso para mim e [é] onde eu tenho me realizado muito profissionalmente, no meu trabalho (P24). 


\section{EtAPA 2: Grupo focal}

As categorias apresentadas nesta etapa foram separadas por temas, por meio da transversalidade temática, que foram: (1) a violência e o profissional de saúde; (2) a importância da estratégia de saúde da família; (3) vínculo com a população; (4) valorização e suporte para os profissionais e (5) estratégias para o atendimento à população vulnerável exposta à violência.

1. A violência e o profissional de saúde, nesta categoria os participantes trataram sobre suas experiências e o trabalho no cenário de violência, dentro e fora da UBS.

Já aconteceu de eu estar com meu colega em campo e o tiroteio está acontecendo ali na nossa frente, sentimos o cheiro da pólvora. (...) Você se depara com uma situação dessa e vê que o risco é real (PGF02).

2. A importância da estratégia de saúde da familia, categoria em que os participantes trouxeram a importância do cuidado e da atenção integral à população e o trabalho na ESF.

O nosso trabalho é baseado na ESF (...). Então nós da ESF temos um olhar diferente, é um vinculo diferente, um olhar do cuidado diferenciado (PGF01).

Existem alguns pressupostos da APS que nos exige uma postura ativa de cuidado com relação à população da nossa área de abrangência. A função da APS é o cuidado. Então nós somos avaliados em cima de ações de promoção, prevenção, incluindo o trabalho de equipe multidisciplinar e com a participação da comunidade (PGF03).

3. Vinculo com a população, os participantes da pesquisa nesta categoria abordaram a importância do vínculo com a população.

(...) E isso criou uma possibilidade enorme de se criar vínculo e cria um conforto muito grande, que é uma relação muito agradável, que é a continuidade do cuidado (PGF03).

4. Valorização / suporte para os profissionais, os profissionais nesta categoria discorreram sobre a importância da qualidade do ambiente de trabalho e o suporte institucional necessário para os mesmos.

Com a reforma, a unidade de saúde ficou mais clara, mais bonita, e todos nós melhoramos, a comunidade melhorou (...) (PGF04).

Eu acho que as equipes de saúde juntamente com a instituição deveriam ser assim: quer prestar assistência nessas áreas, precisa prestar assistência nessas áreas, para estas pessoas, precisa ter uma politica para atender essas pessoas. Acho que a instituição precisa ter uma politica para atendimento às pessoas vulneráveis (PGF03).

5. Estratégias para o atendimento à população vulnerável exposta à violência, nesta categoria descrevem estratégias necessárias junto aos gerentes locais para qualificar o atendimento e evitar exposição ao risco em áreas expostas à violência.

Por isso a importância das reunióes frequentes, porque você fala, troca ideias, te dá um norte [alvo], você para pra pensar um pouco, é muito importante (PGF01).
O contato com as lideranças, eu acho que a gente podia melhorar isso sabe? Até para poder saber, em pontos estratégicos da área, como está a situação. Tem que ter uma comunicação melhor com as lideranças. Devemos nos organizar em rede (PGF05).

\section{DISCUSSÃO}

As estratégias utilizadas na organização do trabalho em saúde em um território de vulnerabilidade social e evidenciadas nesta pesquisa, caracterizaram-se por serem construídas pelos profissionais durante sua atuação e por auxiliarem no planejamento e desenvolvimento do trabalho. Constatou-se nesta pesquisa e na literatura que a violência promove impacto nos profissionais, causando-lhes sentimentos como medo, frustação, impotência e angústia ${ }^{(12)}$.

Referente ao que causa mais impacto foram apontadas situações cuja violência adentra os limites da UBS, tornando esse ambiente inseguro. Todavia, observou-se emergir a capacidade de resiliência dos profissionais da pesquisa, em oferecer um cuidado integral para a população, transcendendo as limitações apresentadas, o que corrobora com estudos em territórios semelhantes ${ }^{(13-14)}$.

Em outro momento, relatam as dificuldades encontradas no atendimento e o acesso aos usuários em períodos mais críticos de violência. Tal fato, condiz com estudos que tratam da violência urbana e situações de confronto mais críticas e revelam diferentes significados e suas consequências relacionadas à construção social, demarcações temporais e espaciais. Circunstâncias em que as regras impostas pelas facções comprometem as ações das equipes de saúde no seu acesso aos domicílios e da população à $\operatorname{UBS}^{(6,15)}$.

Ao relatarem sobre o contato diário com a violência e a importância da ESF, estes profissionais descrevem as estratégias de comunicação que utilizam para avisar uns aos outros quando há perigo ou risco no território, entre elas um aplicativo de celular. As estratégias ao atendimento e vínculo com a população foram evidenciadas respectivamente na primeira etapa que emergiu do âmbito individual e que dividem-se em duas. A primeira com relação à comunicação com o usuário e na qual informaram a importância da comunicação, a fim de evitar ou minimizar conflitos e na segunda, a comunicação entre a equipe em caso de situações de risco, o que enaltece o sentimento de responsabilização ao cuidado com o outro, inferindo o senso de proteção do grupo.

Os resultados desta pesquisa evidenciaram a preocupação dos profissionais de saúde em cumprir com os princípios norteadores da ESF e em destaque, a integralidade do cuidado, o vínculo e a necessidade em trabalhar de forma multi e interdisciplinar. A equipe demonstrou a preocupação com estes princípios, o que para a literatura enaltece o interesse em atender as necessidades de saúde em todas as situações ${ }^{(16)}$. $\mathrm{E}$ ainda, que estes não se sentem alvo da violência armada, mas surpreendidos por ela.

Para se estabelecer o vínculo, uma das estratégias indicadas foi a comunicação assertiva com o usuário, utilizando-a de forma dialógica e empática e que segundo os estudos, tem a intenção de estabelecer interação terapêutica, fundamental para superar modelos de relação de poder e voltar-se ao 
cuidado de acordo com as necessidades das pessoas ${ }^{(17)}$. A estratégia referente à comunicação na equipe, reforça a importância de todos a promoverem sem a presença de ruídos, a fim de minimizar possíveis situações de conflito com a população.

Os profissionais trouxeram ainda no conjunto das falas, o sentimento de proteção coletiva e que revela que o estresse profissional propicia relações, em que uns dão sustento aos outros e desse modo cuidam de si, fato já evidenciado em outro estudo ${ }^{(18)}$. A literatura também destaca que isto seja um processo cultural, cujos saberes científicos, organizacionais e as experiências se articulam e a prática de prevenção de conflitos entre a equipe e usuários se potencializam com os resultados do trabalho, tornando-o um ambiente organizacional saudável ${ }^{(19)}$.

Como meio de proteção a estratégia também citada foi o uso do jaleco dentro e fora da UBS, classificado na literatura com duas finalidades: identificar o profissional de saúde e servir como equipamento de proteção individual. Relacionado à biossegurança está veiculado à Lei Federal $\mathrm{n}^{\circ} 11.105$, de 25 de março de $2005^{(20)}$ e quanto à utilização institucional como forma de identificação pessoal, está ligado ao reconhecimento como profissional de saúde ${ }^{(21)}$, corroborando com os resultados da pesquisa.

Evidenciou-se que o vínculo com a comunidade adscrita proporciona além do atendimento focado nas necessidades das pessoas, também um meio de proteção em períodos críticos de violência, pois os profissionais relataram que são avisados pela comunidade sobre possíveis riscos. Fato este, caracterizado em um estudo, ao citar que o vínculo com a população, grupos operativos e líderes comunitários, propiciam aproximação e favorece a construção conjunta de alternativas diante da violência vivenciada ${ }^{(22)}$.

Ressalta-se que esse vínculo se estende a todos e sem distinção, sendo assim, esse cuidado é direcionado ao agredido e ao agressor e, portanto, não cabe julgamento profissional, mas orientações frente às situações de violência. Ao repensar a prática profissional e após suas experiências permeadas pela violência, os profissionais entendem que suas ações não se limitam ao atendimento de doenças, o que vai ao encontro de um dos princípios norteadores da ESF, a integralidade do cuidado e é relevante para a ampliação de aspectos culturais da vida social e do contexto familiar ${ }^{(23)}$.

Frente às dificuldades no atendimento em territórios vulneráveis expostos à violência, surgiu a temática sobre a logística no que se refere à questão estrutural e insumos. A UBS, cenário deste estudo, passou por revitalização em 2015, o que para os participantes otimizou o acolhimento e a comunidade reagiu positivamente às mudanças. Corroborando com a literatura, a falta de estrutura adequada para a execução das atividades e condições desfavoráveis para o trabalho geram sofrimento, adoecimento e levam à situação de violência ${ }^{(14)}$.

Sobre como se sentem em seu local de trabalho, um estudo revelou que as situações violentas podem gerar uma maior movimentação de funcionários, o que causa descontinuidade do cuidado e enfraquecimento do vínculo ${ }^{(15)}$. Entretanto, destacou-se entre os profissionais desta pesquisa, a satisfação no trabalho e sentimento de acolhimento pela comunidade, fato que vai ao encontro de uma literatura que destacou que a atuação em um universo de alta vulnerabilidade promove sentimento de responsabilidade, utilidade e satisfação, pois suscita o sentimento de cumprir sua atividade de forma coerente enquanto cidadão, mesmo paralelo ao cansaço mental e físico pelas situações vivenciadas ${ }^{(24)}$.

Para o gerenciamento dos serviços de APS em locais vulneráveis e expostos à violência, torna-se um desafio estimular o vínculo entre profissionais e usuários. É consenso entre os profissionais que a integração da equipe e o ambiente agradável no trabalho impactam na oferta do serviço. A literatura nos mostra que, as atividades desenvolvidas em um ambiente com um clima organizacional favorável promovem conforto e facilidade, com produção de maior satisfação e desenvolvimento das potencialidades profissionais ${ }^{(25)}$.

Ainda assim, há um deserto na literatura no que se refere à protocolos, proteção de equipe, bem como organização de processos de trabalho, como descrito em estudo que aborda sobre a fragilidade política e pouco envolvimento institucional, conferindo a necessidade de políticas públicas voltadas às ações de prevenção e enfrentamento da violência, seja ela em qualquer quesito ${ }^{(23)}$.

Com relação às limitações da pesquisa, citam-se os fatos de ter sido realizada em uma única UBS e a concentração das falas no grupo focal pelos profissionais de nível superior, principalmente médicos e dentistas.

\section{CONCLUSÃO}

A violência tem sido vivenciada em vários territórios onde equipes de APS atuam e, para seu enfrentamento neste contexto faz-se necessária uma ação multiprofissional e interdisciplinar na elaboração de estratégias de prevenção à violência. Espera-se que as estratégias de gerenciamento, identificadas nesta pesquisa, a saber: comunicação, proteção coletiva, uso do jaleco e crachá de identificação, estabelecimento de vínculo, integralidade do cuidado, integração da equipe, clima organizacional favorável, organização e organização do trabalho de forma a atender às necessidades de saúde da população, possam auxiliar outras equipes em cenários semelhantes, tendo em vista que a violência, apesar de ser considerada um problema de saúde pública, ainda apresenta pouca visibilidade entre os profissionais e gestores de saúde.

Entre as estratégias discutidas, a comunicação foi citada como uma das principais ferramentas para se evitar exposição aos conflitos e riscos relacionados à violência no território. Neste contexto e de maneira informal, por se tratar de uma estratégia elencada pela equipe, destaca-se o uso de aplicativos como o Whats $A p p^{\circledR}$, que promovem comunicação rápida entre os profissionais no aviso de situações de risco no território. Ainda sobre a comunicação com vistas a evitar conflitos, destaca-se o diálogo assertivo durante os atendimentos, aliado ao uso de palavras que acolham as necessidades de saúde e por meio da escuta ativa, sem impor julgamentos e pré-conceitos.

A postura de sempre estar pronto para estabelecer vínculo mostra uma estratégia positiva. Nesse contexto, com relação 
à comunicação com a equipe, o gerente local possui responsabilidade de promover e manter uma comunicação eficaz como estratégia de conexão e resolução de situações conflituosas. Quanto ao atendimento às necessidades da comunidade, evidencia-se que as diretrizes curriculares da formação dos profissionais de saúde apresentam pouca informação acerca do enfrentamento e atendimento ao cidadão em situações permeadas à violência. É preciso discutir essa formação para além do modelo biomédico, colocando em evidência a atuação multiprofissional, intersetorial e dos determinantes sociais de saúde.
A pesquisa identificou lacunas em relação ao apoio em situações críticas e traz uma proposta voltada às políticas públicas sobre o tema por meio da elaboração de protocolos específicos na organização e gerenciamento da APS em territórios de alta vulnerabilidade expostos à violência e que estabeleçam mecanismos de suporte técnico e emocional a essas equipes a fim de embasar, nortear e apoiar sua atuação diária.

Destaca-se a notoriedade do vínculo, a preocupação da equipe com os usuários e a satisfação dos profissionais por estarem presentes naquele local.

\section{RESUMO}

Objetivo: Identificar estratégias de gerenciamento utilizadas pelas equipes de Estratégia Saúde da Família de uma Unidade Básica de Saúde na organização do trabalho em território de vulnerabilidade social exposto à violência. Método: Estudo de caso único de abordagem qualitativa, em uma unidade de saúde da família localizada na região Sul do Brasil. Coleta de dados por entrevistas individuais com 27 profissionais de saúde de agosto a setembro de 2017 e grupo focal com 18 participantes em abril de 2018. Organização e processamento dos dados com suporte do software IRAMUTEQ e, posteriormente, técnica de análise de conteúdo. Resultados: As cinco classes caracterizaram estratégias utilizadas pelos profissionais ao atendimento à população considerando sua vivência frente a situações de violência. No grupo focal, foi elaborada e validada uma diretriz para nortear o gerenciamento e organização do trabalho nesses serviços. Conclusão: Foi evidenciado que mesmo sem apoio de políticas públicas específicas a essas situações, os profissionais desenvolvem estratégias que incluem o fortalecimento da equipe como forma de proteção coletiva, acolhimento focado no atendimento integral e vínculo. A população é aliada ao facilitar o acesso ao atendimento de vulneráveis e alerta os profissionais das situações críticas no território.

\section{DESCRITORES}

Violência; Vulnerabilidade Social; Profissionais de Saúde; Enfermagem de Atenção Primária; Saúde da Família.

\section{RESUMEN}

Objetivo: Identificar estrategias de gerenciamiento utilizadas por los equipos de Estrategia de Salud de la Familia de una Unidad Básica de Salud en la organización do trabajo en territorio de vulnerabilidad social expuesto a la violencia. Método: Estudio de caso único de abordaje cualitativa, en una unidad de salud de la familia localizada en la región Sur de Brasil. Colecta de dados a través de entrevistas individuales con 27 profesionales de salud de agosto a septiembre de 2017 y grupo focal con 18 participantes en abril de 2018. Organización y procesamiento de los dados con suporte del software IRAMUTEQy, posteriormente, técnica de análisis de contenido. Resultados: Las cinco clases caracterizaran estrategias utilizadas pelos profesionales al atendimiento a la populación considerando su vivencia frente a situaciones de violencia. En el grupo focal, fue elaborada y validada una directriz para nortear el gerenciamiento y la organización del trabajo en eses servicios. Conclusión: Fue evidenciado que mismo sin apoyo de políticas públicas específicas a esas situaciones, los profesionales desenvuelven estrategias que incluyen el fortalecimiento de lo equipo como forma de protección colectiva, acogimiento condensado en el atendimiento integral y vínculo. La populación es aliada al facilitar el acceso al atendimiento de vulnerables y alerta a los profesionales sobre situaciones críticas en el territorio.

\section{DESCRIPTORES}

Violencia; Vulnerabilidad Social; Personal de Salud; Enfermería de Atención Primaria; Salud de la Familia.

\section{REFERÊNCIAS}

1. Brasil. Ministério da Saúde. Portaria n. 2.436, de 21 de setembro de 2017. Aprova a Política Nacional de Atenção Básica, estabelecendo a revisão de diretrizes para a organização da Atenção Básica, no âmbito do Sistema Único de Saúde [Internet]. Brasília; 2017 [citado 2017 out. 10]. Disponível em: http://bvsms.saude.gov.br/bvs/saudelegis/gm/2017/prt2436_22_09_2017.html

2. Arantes LJ, Shimizu HE, Merchán-Hamann E. Contribuições e desafios da Estratégia Saúde da Família na Atenção Primária à Saúde no Brasil: revisão da literatura. Ciênc Saúde Coletiva [Internet]. 2016 [citado 2018 set. 20];21(5):1499-599. Disponível em: http://www.scielo. br/scielo.php?pid=S1413-81232016000501499\&script=sci_abstract\&tlng=pt

3. Silva-Júnior FL, Pedrosa JIS. Territorialization in Primary Health Cary: an experience in medical education. Interface (Botucatu) [Internet]. 2017 [cited 2018 Dec 13];21(1 Suppl):1345-54. Available from: http://www.scielo.br/scielo.php?script=sci_arttext\&pid=S1414$32832017000501345 \& \operatorname{lng}=\mathrm{en}$

4. Machado CB, Daher DV. Violência urbana: repercussões e consequências na assistência à saúde em uma Unidade de Saúde da Família. Cienc Cuid Saúde [Internet]. 2015 [citado 2018 nov. 19];14(4):1445-52. Available from: http://www.periodicos.uem.br/ojs/index.php/ CiencCuidSaude/article/view/24480

5. International Labour Organizational. Joint Programme Launches new Initiative Against Workplace Violence in the Health Sector [Internet]. Geneva: ILO; 2008 [cited 2018 Set 19]. Available from: https://www.ilo.org/global/about-the-ilo/newsroom/news/WCMS_007817/lang--en/index.htm

6. Gonçalves HCB, Queiroz MR, Delgado PGG. Violência urbana e saúde mental: desafios de uma nova agenda? Fractal Rev Psicol [Internet]. 2017 [citado 2018 out. 10];29(1);17-23. Disponível em: http://www.scielo.br/scielo.php?script=sci_arttext\&pid=S1984$02922017000100017 \& \operatorname{lng}=$ en \&nrm=iso

7. Yin RK. Estudo de caso: planejamento e métodos. Porto Alegre: Bookman; 2015.

8. Curitiba. Prefeitura Municipal. Decreto nº 155, de 29 de setembro de 2017. Institui o Índice de Vulnerabilidade das Áreas de Abrangência das Unidades Municipais de Saúde - IVAB na Secretaria Municipal de Saúde de Curitiba [Internet]. Curitiba; 2017 [citado 2017 out. 19$].$ Disponível em: https://www.jusbrasil.com.br/diarios/162638821/dom-ctba-normal-29-09-2017-pg-54?ref=previous_button 
9. Souza MAR, Wall ML, Thuler ACMC, Lowen IMV, Peres AM. The use of IRAMUTEQ software for data analysis in qualitative research. Rev Esc Enferm USP. 2018;52:e03353. DOI: http://dx.doi.org/10.1590/S1980-220X2017015003353

10. Camargo BV, Justo AM. IRAMUTEQ: um software gratuito para análise de dados textuais. Temas Psicol [Internet]. 2013 [citado 2015 out 10];21(2):513-8. Disponível em: http://pepsic.bvsalud.org/pdf/tp/v21n2/v21n2a16.pdf

11. Bardin L. Análise de conteúdo. Lisboa: Edições 70; 2016.

12. Bordignon M, Monteiro, MI. Violence in the workplace in Nursing: consequences overview. Rev Bras Enferm. 2016;69(5):939-42. DOI: http://dx.doi.org/10.1590/0034-7167-2015-013

13. Cardoso MCC, Pereira MD, Moreira DA, Tibães ABB, Ramos FRS, Brito MJM. Moral Distress in Family Health Strategy: experiences expressed by daily life. Rev Esc Enferm USP. 2016;50(n.spe):89-95.

14. Pinto AGA, Jorge MSB, Marinho MNASB, Vidal ECF, Aquino PS, Vidal ECF. Experiences in the Family Health Strategy: demands and vulnerabilities in the territory. Rev Bras Enferm. 2017;70(5):920-7. DOl: http://dx.doi.org/10.1590/0034-7167-2015-0033

15. Benício LFS, Barros JPP. Estratégia Saúde da Família e violência urbana: abordagens e práticas sociais em questão. Sanare (Sobral). 2017;16 Supl 1:S102-12.

16. Merhy EE, Baduy RS, Seixas ST, Almeida DES, Slomp Junior H. Avaliação compartilhada do cuidado em saúde: surpreendendo o instituído nas redes. Rio de Janeiro: Hexis; 2016.

17. Coriolano-Marinus MWL, Queiroga BAM, Ruiz-Moreno L, Lima LS. Comunicação nas práticas em saúde: revisão integrativa da literatura. Saúde Soc [Internet]. 2014 [citado nov.18];23(4):1356-69. Disponível em: http://www.scielo.br/scielo.php?script=sci_arttext\&pid=S0104$12902014000401356 \& \operatorname{lng}=\mathrm{en}$

18. Kanno NP, Bellodi PL, Tess BH. Profissionais da estratégia saúde da família diante de demandas médico-sociais: dificuldades e estratégias de enfrentamento. Saúde Soc [Internet]. 2012 [citado 2017 abr. 10];21(4):884-94. Disponível em: http://www.scielo.br/scielo.php?script=sci_ arttext\&pid=S0104-12902012000400008

19. Cunha P, Meneses R, Oliveira MC. Gestão de conflitos na área de saúde: uma proposta de reflexão. Arq Med [Internet]. 2013 [citado 2018 dez. 12];27(3):132-4. Disponível em: http://www.scielo.mec.pt/scielo.php?script=sci_arttext\&pid=S0871-34132013000300006\&lng=pt

20. Brasil. Lei n. 11.105, de 25 de março de 2005. Estabelece normas de mecanismos de fiscalização de atividades que envolvam organismos geneticamente modificados e seus derivados, cria o conselho nacional de biossegurança, reestrutura a comissão técnica nacional de biossegurança, dispõe sobre a política nacional de biossegurança e dá outras providências [Internet]. Brasília; 2005 [citado 2017 mar. 15]. Disponível em: http://www.planalto.gov.br/ccivil_03/_Ato2004-2006/2005/Lei/L11105.htm

21. Fontanella BJB, Silva, FRS, Gomes R. Rituais e símbolos na atenção formal à saúde: o caso do vestuário profissional na ótica de pacientes da Atenção Básica. Physis [Internet]. 2012 [citado 2017 set. 20];22(4): 507-25. Disponível em: http://www.scielo.br/scielo.php?pid=S0103$73312012000200006 \&$ script=sci_abstract\&tlng=pt

22. Batista CB, Campos AS, Reis JC, Schall VT. Violência no trabalho em saúde: análise em unidades básicas de saúde de Belo Horizonte, Minas Gerais. Rev Trab Educ Saúde [Internet]. 2011 [citado 2017 out. 17];9(2);295-317. Disponível em: http://www.scielo.br/scielo. php?pid=S1981-77462011000200008\&script=sci_abstract\&tlng=pt

23. Guzzo PC, Costa MC, Silva EB, Jahn AC. Healthcare practices for users suffering from violence: from invisibility to comprehensive (un) care. Rev Gaúcha Enferm [Internet]. 2014 [cited 2018 Oct 20];35(2):100-5. Available from: http://www.scielo.br/scielo.php?script=sci_ar ttext\&pid=S1983-14472014000200100

24. Donoso MTV, Bastos MAR. O cotidiano dos profissionais que trabalham diretamente com vítimas de violência social. Rev Enferm Cent Oeste Min. 2104;4(1):951-60.

25. Santos LJ, Paranhos MS Family Health Teams workers in Rio de Janeiro: leadership aspects in a study on organizational climate. Ciênc Saúde Coletiva [Internet]. 2017 [cited 2018 Nov 22];22(3):759-69. Available from: http://www.scielo.br/pdf/csc/v22n3/en_1413-8123csc-22-03-0759.pdf 